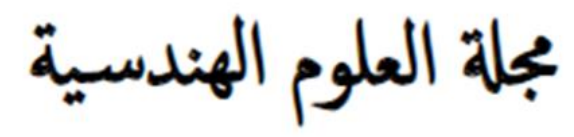

\title{
Efficiency of Vierendeel Girder, Post-tensioned Girders and Steel Beams for Long Cantilevers in Buildings
}

\section{Faisal Fadlelbari ${ }^{1, *}$}

1 Civil Engineering Department, Omdurman Islamic University, Omdurman, Sudan

* Corresponding author: M. Faisal Fadlelbari (e-mail: fadla faisal@hotmail.com).

Article history: Received 30 March 2020, Received in revised form 4 November 2020, Accepted 11 November 2020

\begin{abstract}
Cantilevers are a part of our life, they are everywhere: bridges, building's balconies, traffic signs, car parking shades even the aircraft's wings. The long cantilevers of the buildings always present as a big challenge to structural engineers in their practice life. The structural behavior of these cantilevers depends on a several factors, such as rigidity of the slab, rigidity of columns or walls, span continuity... etc. But the real dilemma lies in the economical choice. This paper focused on the cantilever's structural analysis according to the used structural. Moreover, it shows a comparison between three structural system choices: Vierendeel Girder, Post - Tensioned Girders and Steel Composite Beam in a graph. The objective of this paper is to give a guideline to the structural engineers to choose the optimum system of the building cantilevers according to the factors mentioned earlier. At the end, the paper illustrated the Vierendeel girder is the most efficient system for cantilevers. Accordingly, recommendations result on that up to $4.0 \mathrm{~m}$ cantilever length steel beams will be enough, for more than 4.0 and less than or equal to $6.0 \mathrm{~m}$ post-tension is recommended, and for more than $6.0 \mathrm{~m}$ cantilever we should use Vierendeel girder.
\end{abstract}

Keywords: Post-tensioned Girders, Steel Beams, Vierendeel Girders.

\section{INTRODUCTION}

The structural Analysis of the cantilevers can be calculated by statics methods. The structural indeterminacy doesn't affect the results. Since the structure is stable the moments will be $\left(\mathrm{wL}^{2} / 2\right)$, where $\mathrm{w}$ represent the distributed load and $\mathrm{L}$ represent the span length. Similarly, the shear force will be (W.L). Cantilever moment and shear is large if compared against the total span moment of the both side supported beam which is $\left(\mathrm{wL}^{2} / 8\right)$ as described in Figure (1).

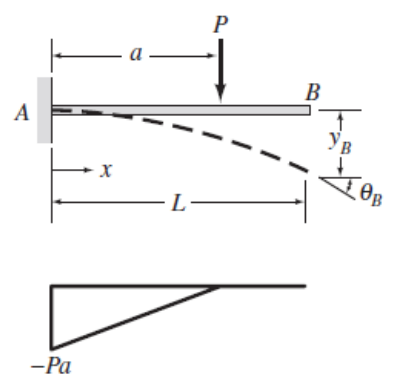

Fig. 1. Cantilevers statics Forces.
Long cantilevers can result on large moments, shears and deflections.

These internal forces can be resisted by the rigidity of the cantilever systems which will be mentioned below.

The world's longest cantilever is in Dubai of the twin towers which is under construction up to the date of this paper writing. This cantilever hangs to $60 \mathrm{~m}$ in the air. And its system can be classified as a Vierendeel girder as shown in Figure (2).

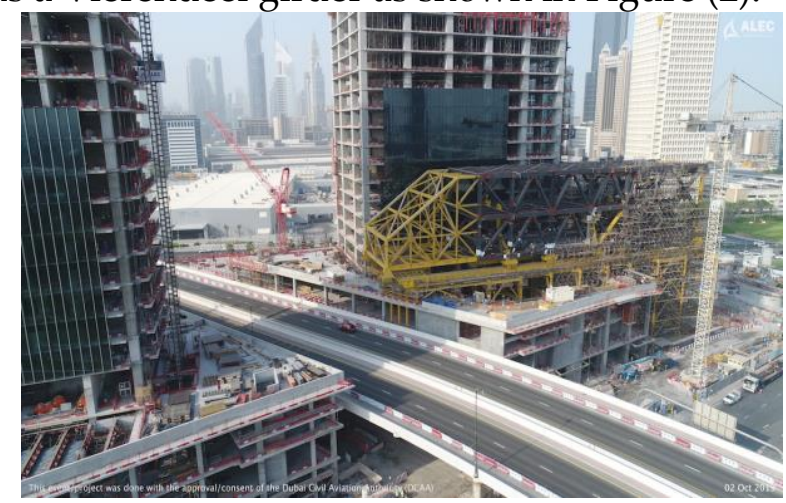

Fig. 2. Dubai Twin Towers Cantilever. 
University of Belval, Luxembourg main campus which is opened in 2005 building contain a $25 \mathrm{~m}$ long cantilever which is made from a post tensioned girder such as in Figures (3) \& (4).

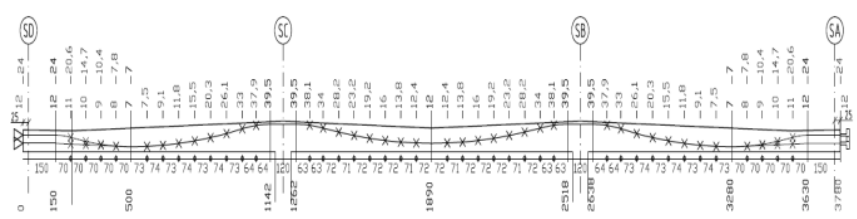

Fig. 3. Belval, Luxembourg University campus cantilever structure details.

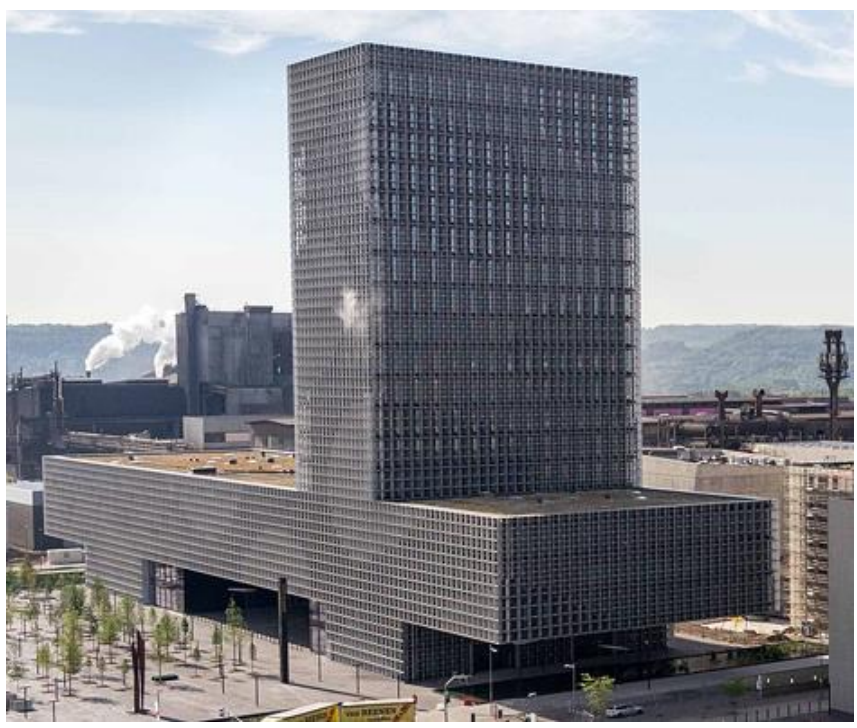

Fig. 4. Belval, Luxembourg University Building.

In San Diego and on California in general there are many times that the architect or designer adds cantilever or free-standing decks and balconies. As in Figure (5), they use a steel deck system.

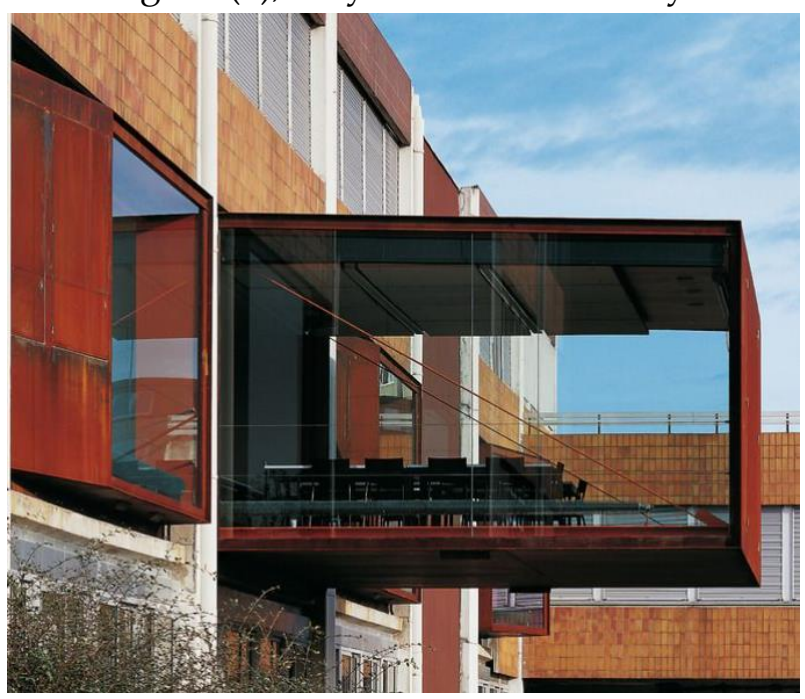

Fig. 5. San Diego city buildings cantilevers.

\section{DIFFERENT SYSTEMS ANALYSIS}

\section{A. Vierendeel Girder}

In 1896 Arthur Vierendeel developed a truss frame bridge by using rigid connections to add more stability to the girder as in Figure (6). In 1902 the first bridge made through Avelgem, Belgium using the development of Vierendeel. Later this development was a famous of Vierendeel Girder.

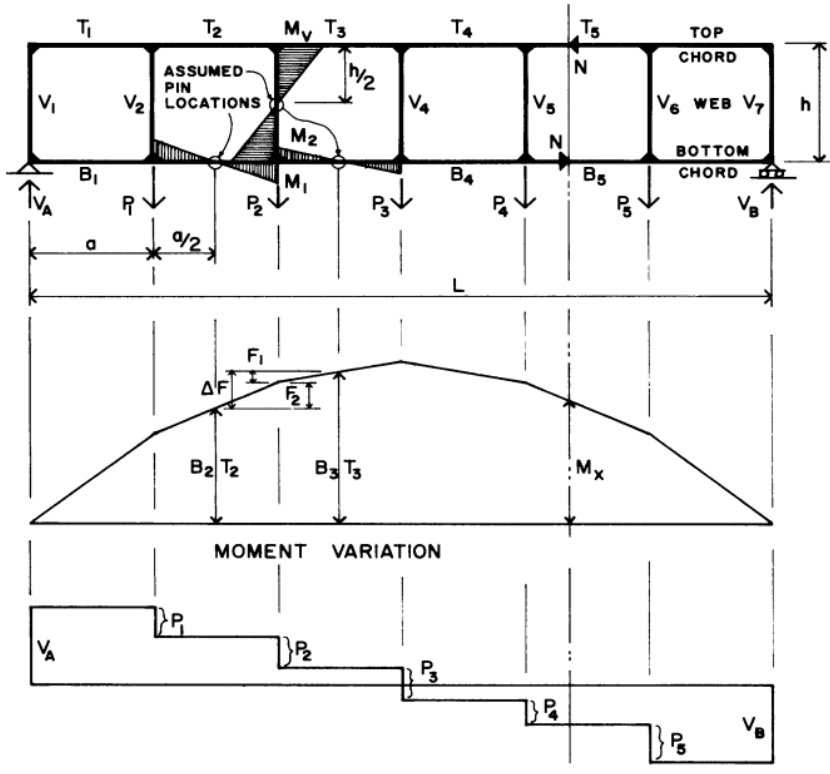

Fig. 6. Vierendeel Girder Analysis.

Although Vierendeel developed the girder to be as solution for bridges as a simply supported, there is many cantilevers for buildings designed as Vierendeel girder for long spans. Such as mentioned above in Figure (2).

For building's cantilevers cases, the girder should be continuous to add more stability.

\section{B. Post Tensioned Girder}

Post tension is that concrete injected by internal forces through tendons to work against the applied load to the beam.

Since 1939 by the invention of the prestressed concrete by its owner Eugène Freyssinet and his book published in France named "Une Revolution dans les Techniques du Baton" and then the researches starts to develop it and its construction methods. The basic idea as it is shown in Figure (7), that an internal force will be applied to the tension fibers (hence the concrete has a good resistance against compression), then the concrete will be casted after tensioning in this 
case will be called prestressed or the tendon will pass through conduits to the edge of the beam then tensioned can be applied in this case this method called post tensioning.

One of the most important advantages of the prestressed concrete is that there is no cracking hence most of the section is applied to compression. Long term deflection only can occur due the creep, temperature and the cable relaxation.

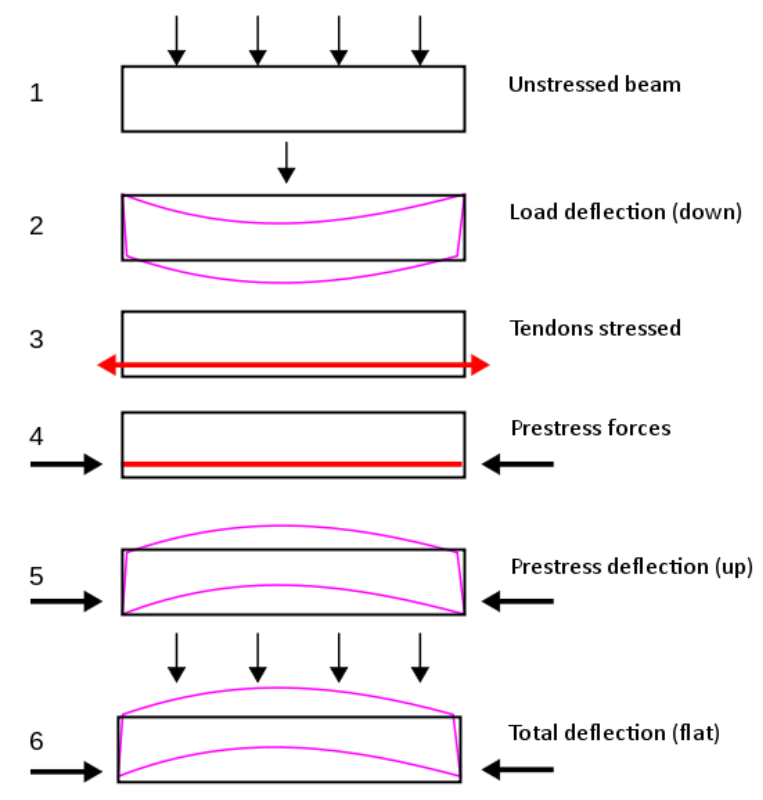

Fig. 7. Prestress concept.

\section{Steel Beams}

Steel structures has been widely used in the $20^{\text {th }}$ century, especially during world war II. The steel as a material is very efficient, its weight is very light, and its strength is very high against compression or tension as shown in Figure (8).

Now a days, software is widely used, and construction Tanique's have been developed, and the biggest advantage of the steel that's it can be formed to any shape easily.

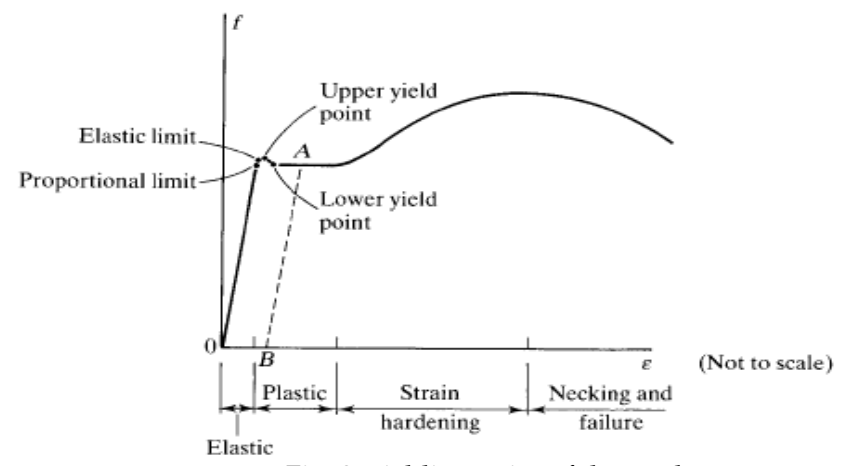

Fig. 8. yielding point of the steel.

\section{DESIGN REQUIREMENTS}

\section{A. Vierendeel Girder}

As stated earlier, Virendeel girder is a system of connected columns and beams, it can be steel or concrete.

The most important members are columns because it will be applied to high amount of moment if it is compared by the axial forces, then the eccentricities will be very high. According to ACI 318-M-19 the column slenderness should be checked using the following chart can be as stated in R6.2.5.3 in figure (9).

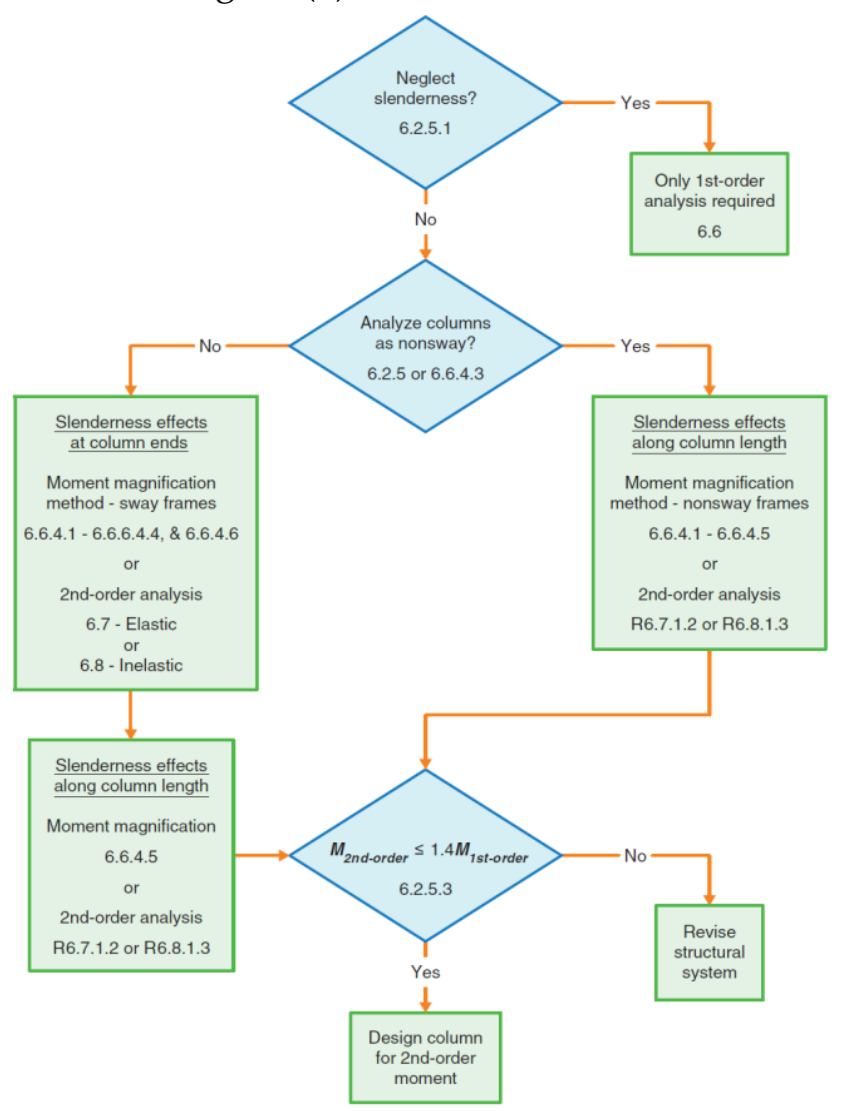

Fig. 9. Determining Slenderness Effect.

If the columns are steel the effect of the slenderness should be checked as well according to AISC according to chart plotted in Figure (10).

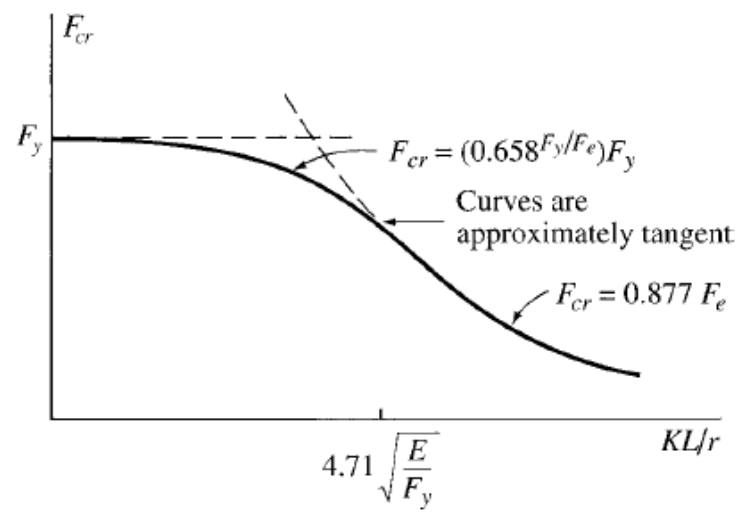

Fig. 10. Slenderness vs. critical buckling stress. 


\section{B. Post- Tensioned Girders}

With the reference of the concept mentioned earlier and according to the assumptions mentioned in ACI 318M-11 section 18.3, the prestressing force should cover the following losses:

1) Prestressing steel seating at transfer.

2) Elastic shortening of concrete.

3) Creep of concrete.

4) Shrinkage of concrete.

5) Relaxation of prestressing steel stress.

6) Friction loss due to intended or unintended curvature in post-tensioning tendons.

Each of the above-mentioned loss estimation are mentioned in ACI 318M-11 section 18.6. As a result, the effective prestressing force is noted to be $\left(\mathbf{f}_{\mathrm{se}}\right)$, according to the effective prestressing force the flexural ultimate strength can be computed from the following equation that's depends on Figure (11).
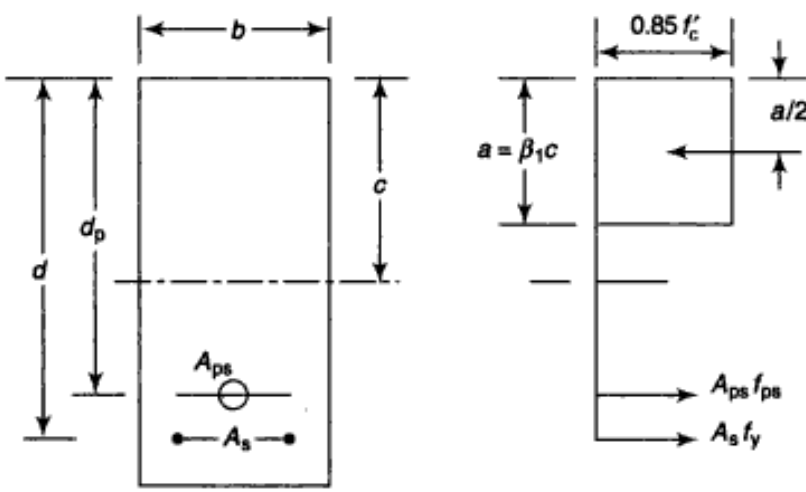

Fig. 11. Strength block of prestress section.

$$
\begin{aligned}
& M_{\mathrm{u}}=\left[A_{\mathrm{pw}} f_{\mathrm{ps}}\left(d_{\mathrm{p}}-\frac{a}{2}\right)+A_{\mathrm{s}} f_{\mathrm{y}}\left(d-\frac{a}{2}\right)\right] \\
& a=\left[\frac{A_{\mathrm{ps}} f_{\mathrm{ps}}+A_{\mathrm{s}} f_{\mathrm{y}}}{0.85 f_{\mathrm{c}}^{\prime} \cdot b}\right]
\end{aligned}
$$

And with the reference to the ACI 318M-11 eq. $(18-1) \mathrm{f}_{\mathrm{ps}}$ can be estimated for the bonded as follow:

$$
f_{p s}=f_{p u}\left\{1-\frac{\gamma_{p}}{\beta_{1}}\left[\rho_{p} \frac{f_{p u}}{f_{c}^{\prime}}+\frac{d}{d_{p}}\left(\omega-\omega^{\prime}\right)\right]\right\}
$$

If the compression reinforcement has been considered, the amount of the box bracket should be not less than 0.17 and $\mathbf{d}$ ' shall not be greater than $\mathbf{0 . 1 5} \mathrm{d}$.
And for the unbonded tendons $\mathbf{f}_{\mathrm{ps}}$ can be estimated for the bonded as follow:

$f_{p s}=f_{s e}+70+\frac{f_{c}^{\prime}}{100 \rho_{p}}$

The ultimate flexural strength should be reduced by $(\varnothing=\mathbf{0 . 9})$ as stated in ACI 318M-11 section 9.2. The minimum reinforcement of the bonded and unbonded tendons should be as follows as stated in ACI 318M-11 eq. (18-4):

$$
A_{s}=0.004 A_{c t}
$$

As stated in ACI 318M-11 for the Two-Way slabs for positive moments areas minimum reinforcement of tendons is not required if the tension stress at the bottom fibers doesn't exceed $\mathbf{0 . 1 7} \mathrm{Vfc}^{\prime}$. If it is exceeded, the minimum reinforcement should be as follow:

$A_{s}=\frac{N_{c}}{0.5 f_{y}}$

In negative moment areas at column supports, the minimum area of bonded reinforcement. As in the top of the slab in each direction shall be computed by

$$
A_{s}=0.00075 A_{c f}
$$

\section{Steel Beams}

The steel beams can be composite if its bonded to a concrete slab, or it can be non-composite if it not bonded to the concrete slab or the deck system used is MS sheet only. And the composite strength is more than the non-composite one.

The fabrication of the steel can be by hot rolled, or Pre-engineered sections assembled.

As stated in AISC manual and Table 3-19, the flexural strength can be determined for the composite sections if the location of the plastic neutral axis is known (PNA) and it is uniquely can be determined by the horizontal shear $\mathrm{f} \Sigma \Sigma Q_{n}$

Alternatively, AISC manual Table 3-19 can be used to check the flexural strength of a composite beam by selecting a valid value of $\left(\Sigma Q_{n}\right)$. With the effective width of the flange $(\mathbf{b})$ determined per AISC specifications section I3.1a, the appropriate value of the distance from concrete flange force to 
beam top flange $\mathrm{Y} 2$ can be determined as in equation (8) and defined in Figure (12)

$Y_{2}=Y_{c o n}-\frac{a}{2}$

Where, $Y_{\text {con }}$ distance from top of steel beam to top of concrete. And (a) can be determined by equation (9) and defined in figure (10).

$a=\frac{\Sigma Q_{n}}{0.85 f_{c}^{\prime} b}$

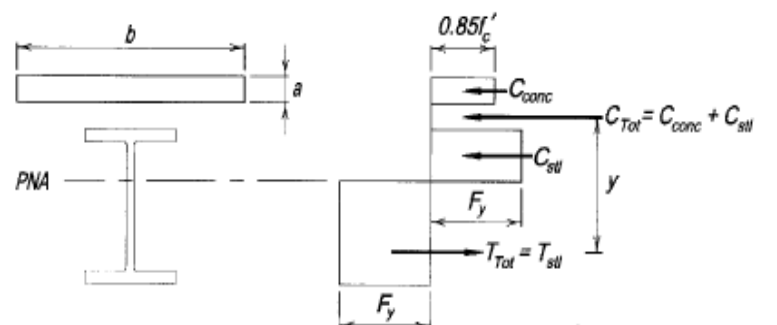

(a)

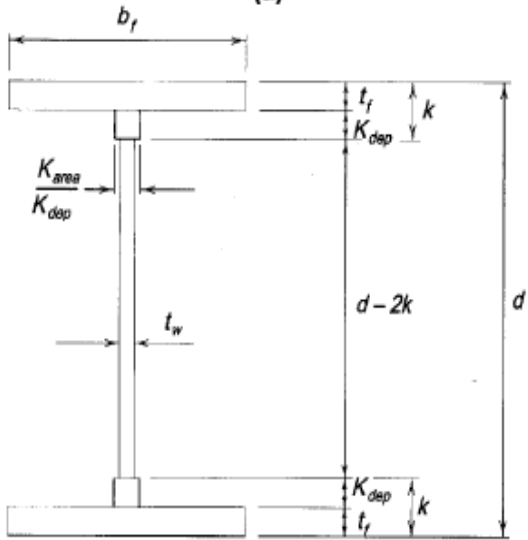

(b)

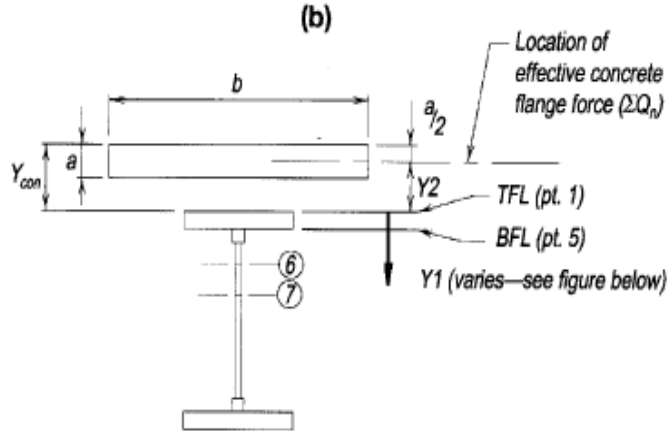

Y1 = Distance from top of steel flange to any

of the seven tabulated PNA locations

$\Sigma Q_{n}(@$ point (6) $)=\frac{\Sigma Q_{n}\left(@ \text { pt. 5) }+\Sigma Q_{n}(@ p t .7)\right.}{2}$

$\Sigma Q_{n}(@$ point(7) $)=0.25 F_{y} A_{s}$

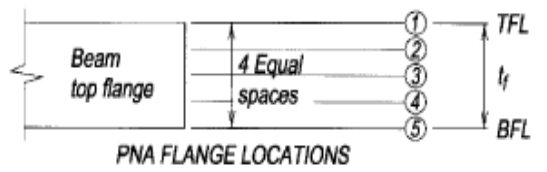

(c)

Fig. 12. Strength Design Models.

\section{CASE STUDY \& DATA}

A frame of 4 stories as in Figure (13) has been studied to evaluate the efficiency of the different system. CSI ETABS has been used for analysis. A different length of cantilever has been used to compare the suitable system. If neglecting the lateral loading because in the case of the long cantilever the effect of the lateral loading is minor. And if considering the span of the perpendicular direction is $4 \mathrm{~m}$ and the slab thickness is $20 \mathrm{~cm}$, and if it was considered that occupancy of the building as a residential building the linear loading can be calculated as follow:

Dead Load $=$ S.W + F.L + P.L

Dead load $=21.6 \mathrm{KN} / \mathrm{m}$.

Live load $=4 \mathrm{KN} / \mathrm{m}$.

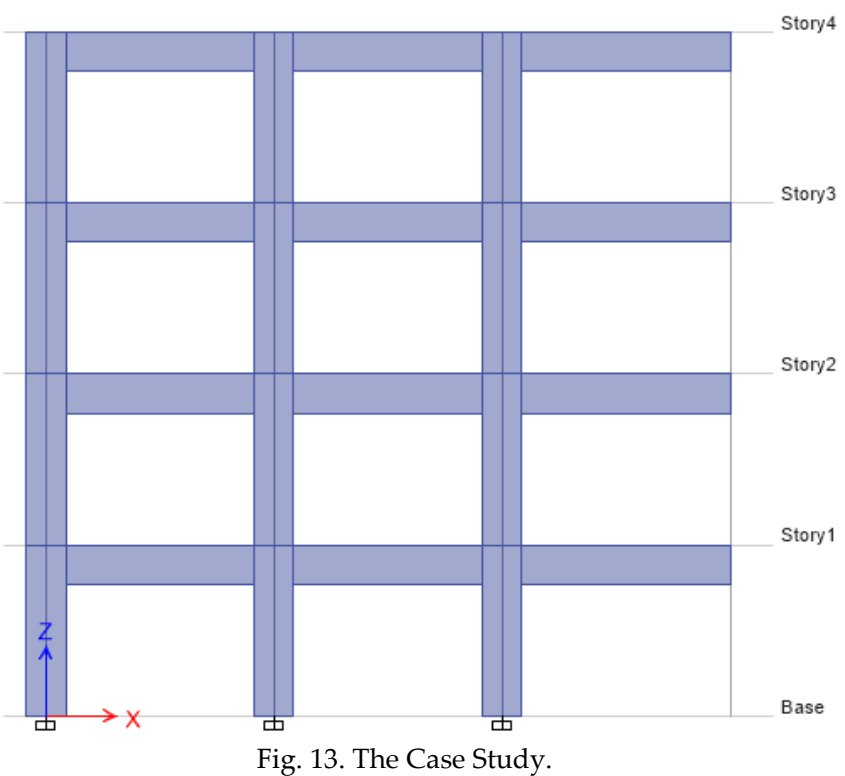

Three systems have been studied as follow:

- The cylindrical strength of the concrete is $28 \mathrm{MPa}$.

- The structural steel grade is ASTM A992.

- The tendon material is A416Gr270.

- The initial tendon jacking force is $293 \mathrm{KN}$.

- The tendon loss stress due to elastic shortening is $186 \mathrm{MPa}$.

- The total long-term loss stress is $93 \mathrm{MPa}$.

- Different profiles for Vierendeel girder are used as described in Figures (14), (15) \& (16). 


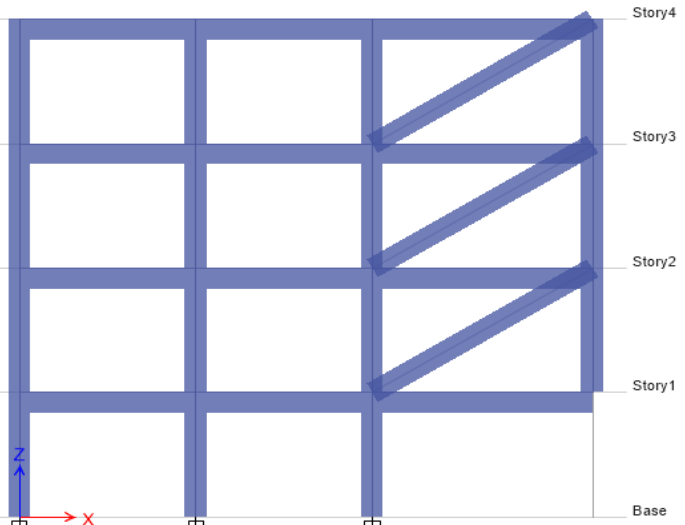

Fig. 14. Virendeel girder profile studied up to $5 \mathrm{~m}$ cantilever.

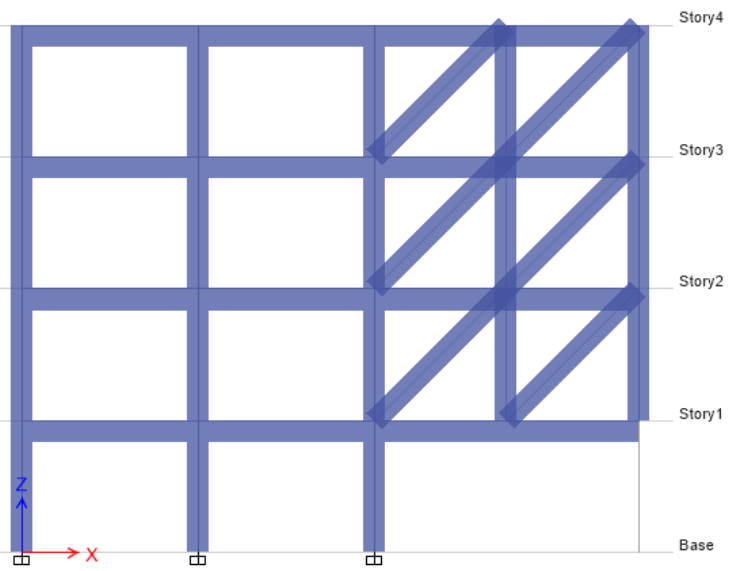

Fig. 15. Virendeel girder profile studied for $6 \mathrm{~m}$ cantilever.

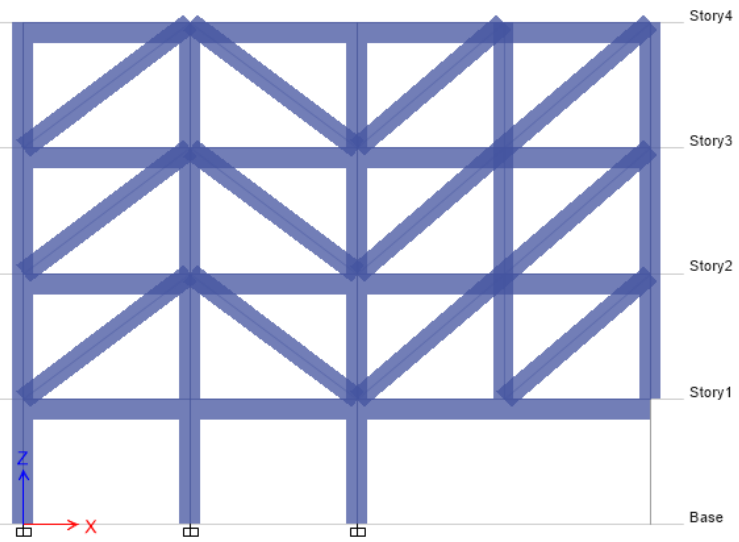

Fig. 16. Virendeel girder profile studied for $7 \mathrm{~m}$ cantilever.

The profile of the tendons for the post tensioned girder as described in Figure (17) for the all cantilever length under study.

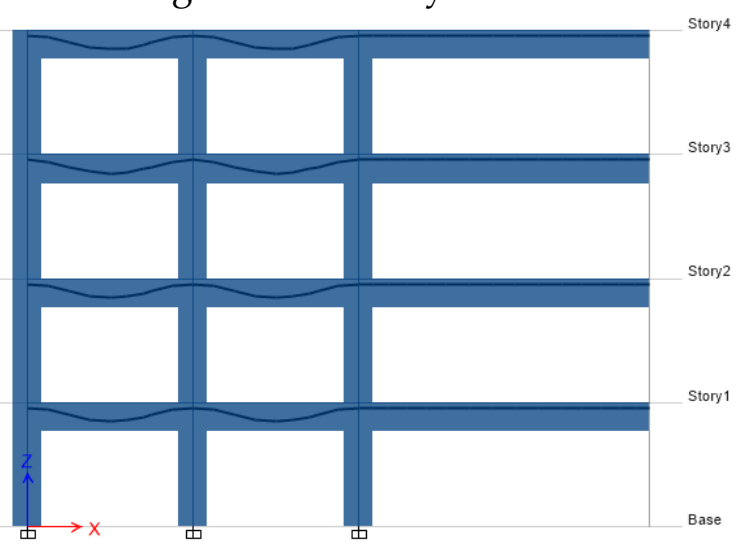

Fig. 18. Post tensioned girder tendon`s profile.

\section{RESULTS \& DISCUSSIONS}

With the reference to the analysis performed above the results show that the maximum moments always occur in the steel beams system as it is shown in Table (1).

The post tensioned girder acting as a propped cantilever, and that as a result of the superposing of the prestressing moments and the external forces moments as shown in Table (2).

The cantilever columns of the Vierendeel girder acting as a supported column and that action result from the continuity of the connected members to act as a one unit as cleared in Table (3).

TABLE 1 : SERVICE MOMENT OF THE STEEL BEAMS OF THE DIFFERENT CANTILEVER LENGTH.

\begin{tabular}{|c|c|c|c|c|}
\hline Span (m) & $\begin{array}{c}\text { Max. } \\
\text { Moment } \\
(\text { KN.m) }\end{array}$ & $\begin{array}{c}\text { Max. Shear } \\
(\mathrm{KN})\end{array}$ & $\begin{array}{c}\text { Max. Axial } \\
(\mathrm{KN})\end{array}$ & $\begin{array}{c}\text { Max. } \\
\text { Deflction } \\
(\mathrm{mm})\end{array}$ \\
\hline 2 & -40.00 & -23.50 & 0.00 & -2.90 \\
\hline 3 & -94.25 & -35.38 & 0.00 & -8.17 \\
\hline 4 & -171.49 & -47.24 & 0.00 & -20.00 \\
\hline 5 & -267.40 & -61.10 & 0.00 & -25.00 \\
\hline 6 & -409.90 & -76.24 & 0.00 & -28.85 \\
\hline 7 & -567.51 & -90.76 & 0.00 & -38.13 \\
\hline
\end{tabular}

TABLE 2 : SERVICE MOMENT OF THE OF THE DIFFERENT CANTILEVER LENGTH.

\begin{tabular}{|c|c|c|c|c|}
\hline Span (m) & $\begin{array}{c}\text { Max. } \\
\text { Moment } \\
(\text { KN.m) }\end{array}$ & $\begin{array}{c}\text { Max. Shear } \\
(\mathrm{KN})\end{array}$ & $\begin{array}{c}\text { Max. Axial } \\
(\mathrm{KN})\end{array}$ & $\begin{array}{c}\text { Max. } \\
\text { Deflction } \\
(\mathrm{mm})\end{array}$ \\
\hline 2 & +29.35 & -21.62 & -238.67 & +0.21 \\
\hline 3 & +29.35 & -33.97 & -238.67 & -1.67 \\
\hline 4 & -57.52 & -46.34 & -238.67 & -7.68 \\
\hline 5 & -110.03 & -58.69 & -238.67 & -20.843 \\
\hline 6 & -153.37 & -72.09 & -358.02 & -27.96 \\
\hline 7 & -187.60 & -88.43 & -477.35 & -20.25 \\
\hline
\end{tabular}


TABLE 3: SERVICE MOMENT OF THE VIRENDEEL GIRDERS OF THE DIFFERENT CANTILEVER LENGTH.

\begin{tabular}{|c|c|c|c|c|}
\hline Span (m) & $\begin{array}{c}\text { Max. } \\
\text { Moment } \\
(\text { KN.m) }\end{array}$ & $\begin{array}{c}\text { Max. Shear } \\
(\mathrm{KN})\end{array}$ & $\begin{array}{c}\text { Max. Axial } \\
(\mathrm{KN})\end{array}$ & $\begin{array}{c}\text { Max. } \\
\text { Deflction } \\
(\mathrm{mm})\end{array}$ \\
\hline 2 & -23.35 & -38.80 & -73.41 & -2.01 \\
\hline 3 & -37.40 & -51.17 & -103.04 & -4.39 \\
\hline 4 & -58.24 & -65.31 & -150.10 & -8.77 \\
\hline 5 & -85.44 & -79.98 & -207.32 & -15.51 \\
\hline 6 & -89.95 & -71.53 & -333.02 & -25.55 \\
\hline 7 & -53.97 & -62.23 & -555.35 & -9.13 \\
\hline
\end{tabular}

From the analysis results mentioned above the trials have been studied for cantilever lengths started from $2 \mathrm{~m}$ up to $7 \mathrm{~m}$, and members design have been followed to obtain the maximum demand capacity ratio with the respect of the design requirement to evaluate the comparisons between the different systems. The cantilever deflection is the most useful factor that can be

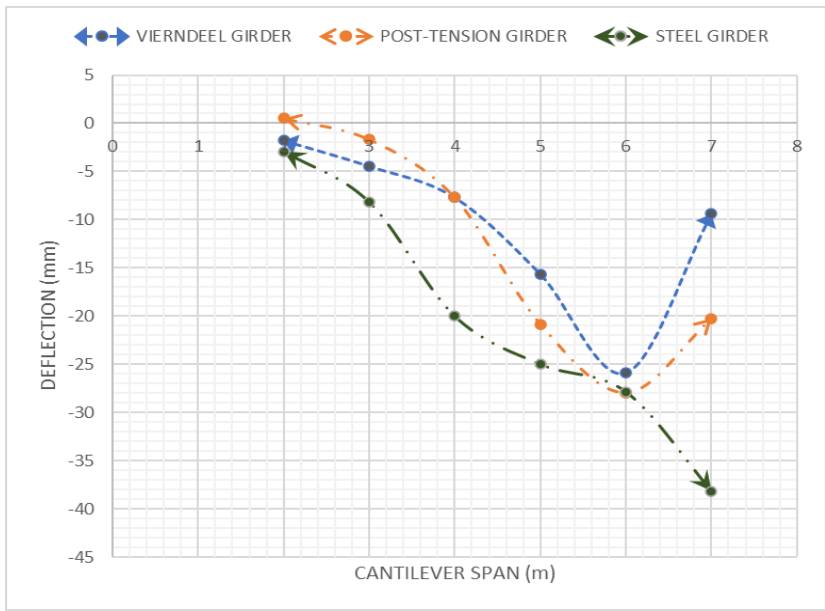

used for the comparison. As a result, the graph has been plotted in Figure (22).

Fig. 22. The comparison between different systems.

From Figure (22), it was noticed that post tension girder is efficient system up to the $4 \mathrm{~m}$ cantilever length, then Vierendeel girder appears as difficult competitor against the post tension girder up to the $6 \mathrm{~m}$ length then the Vierendeel only is the winner. The steel beam always fails against the other compared.

\section{CONCLUSIONS}

The most efficient system for the buildings cantilevers due the gravity load is the Vierendeel girder.

\section{RECOMMENDATIONS}

Up to $4.0 \mathrm{~m}$ cantilever length steel beams system can be enough hand over the loads safely.

More than $4.0 \mathrm{~m}$ and less than $6.0 \mathrm{~m}$ cantilever length post-tensioned beams should be used to transfer the load.

More than $6.0 \mathrm{~m}$ cantilever length Vierendeel girder should be used.

\section{REFERENCES}

[1] D. Hegyi, and A. A. Sipos, "A Post-tensioned concrete slab cantilevering 6.5m," Research gate, article in structural concrete, January 2011.

[2] Q. Wang, W. L. Qiu and S. Li Xu, "Structural Optimization of Steel Cantilever Used in Concrete Box Girder Bridge Widening," Hindawi Publishing Corporation, 2015, ID 105024, 2015.

[3] D. J. Wickersheimer, "The Vierendeel" Journal of the Society of Architectural Historians, Vol. 35, No. 1, pp. 54-60, March 1976.

[4] I. Lukacevic, D. Dujmovic "Combined Lattice and Vierendeel Girder in Long Span Steel Frame Research gate, article July 2016.

[5] J. Almeida, J. Camara, T. Friedrich, J. Marc, Post-tensioning in Buildings, 1st ed. Lausanne, Switzerland.: International Federation for Structural Concrete, 2005.

[6] F. A. Zahan, R. Ganz, Post-tensioned in Buildings, 4th ed. Canada.: VSL international ltd., 1992.

[7] W. T. Segui, "Steel Design", 1st ed., 4th ed., Canada.: Nelson a division of Thomson., 2007.

[8] G. Qiang, J. Jun Li, "Advanced Analysis and Design of Steel Frames", 1st ed., West Sussex, England.: John Wiley \& Sons Ltd., 2007.

[9] T. Y. Lin, "Design of Prestressed Concrete Structures", 3rd ed., New York, USA.: John Wiley \& Sons Ltd., 1981.

[10] N. K. Raju, "Prestressed Concrete", 4th ed., New York, USA.: McGraw-Hill, 2007.

[11] American Concrete Institute, ACI 318M-19.

[12] American Institute of Steel Constructions, AISC Manual 13th Edition. 